US Army Corps of Engineers ${ }_{\circledast}$

Engineer Research and

Development Center

Navigation Systems Research Program

\title{
Risk-Based Prioritization of Operational Condition Assessments: Stakeholder Analysis and Literature Review
}

Jonathan K. Alt, Willie H. Brown, George E. Gallarno,

March 2021

and John P. Richards

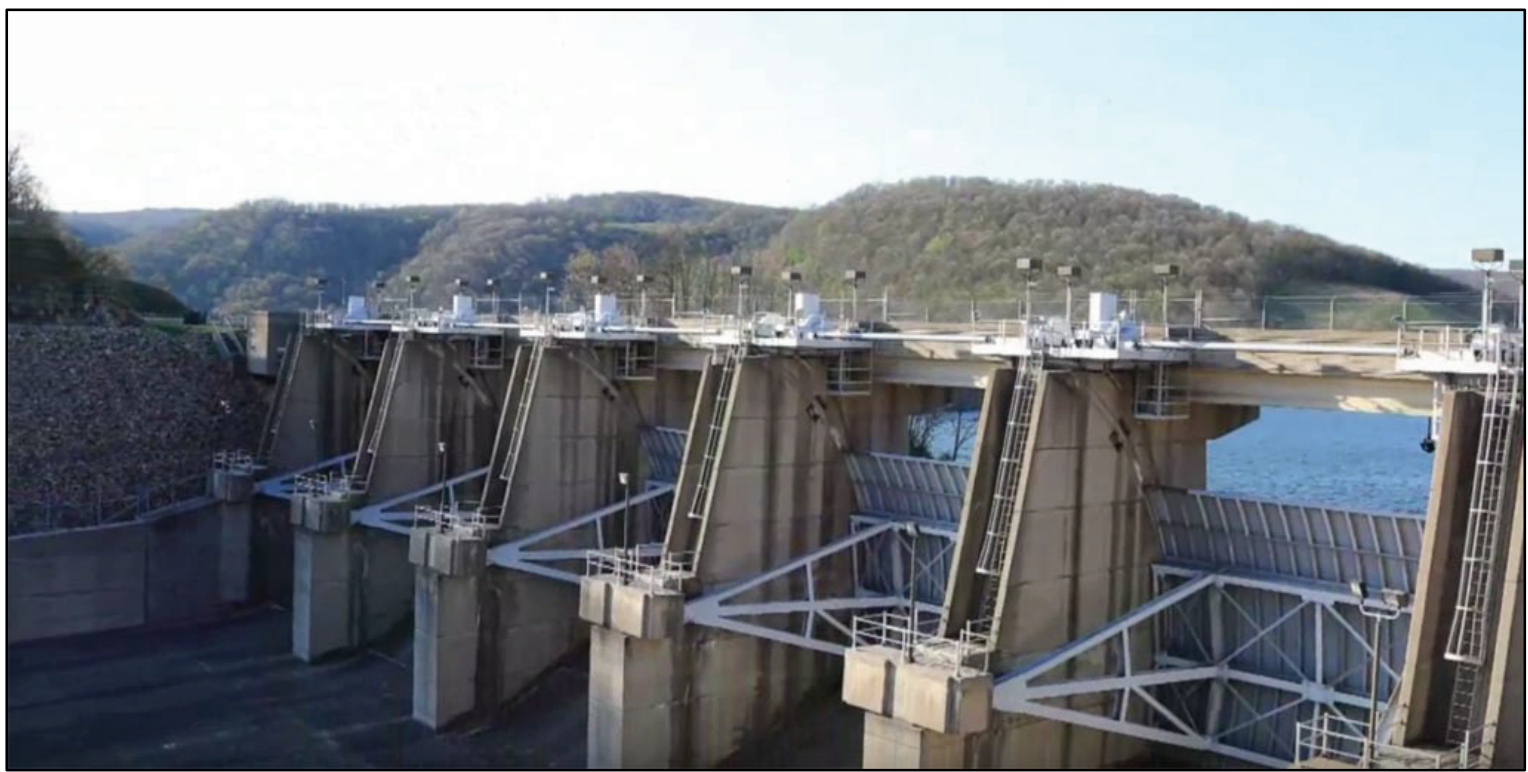


The US Army Engineer Research and Development Center (ERDC) solves the nation's toughest engineering and environmental challenges. ERDC develops innovative solutions in civil and military engineering, geospatial sciences, water resources, and environmental sciences for the Army, the Department of Defense, civilian agencies, and our nation's public good. Find out more at www.erdc.usace.army.mil.

To search for other technical reports published by ERDC, visit the ERDC online library at https://erdclibrary.on.worldcat.org/discovery. 


\title{
Risk-Based Prioritization of Operational Condition Assessments: Stakeholder Analysis and Literature Review
}

\author{
Jonathan K. Alt, Willie H. Brown, George E. Gallarno, and John P. Richards \\ Information Technology Laboratory \\ US Army Engineer Research and Development Center \\ 3909 Halls Ferry Road \\ Vicksburg, MS 39180-6199
}

Final report

Approved for public release; distribution is unlimited.

\author{
Prepared for Navigation Systems Research Program \\ Coastal Hydraulics Laboratory \\ US Army Engineer Research and Development Center \\ Vicksburg, MS 39180-6199 \\ Under Funding Account Code U4375151; AMSCO Code 031391
}




\section{Abstract}

The US Army Corps of Engineers (USACE) operates, maintains, and manages more than $\$ 232$ billion worth of the Nation's water resource infrastructure. Using the Operational Condition Assessment (OCA) system, the USACE allocates limited resources to assess conditions and maintain assets in efforts to minimize risks associated with asset performance degradation. Currently, OCAs are conducted on each component within a facility every 5 years, regardless of the component's risk contribution. The analysis of risks associated with Flood Risk Management (FRM) facilities, such as dams, includes considering how the facility contributes to its associated FRM watershed system, understanding the consequences of degradation in the facility's performance, and calculating the likelihood that the facility will perform as expected given the current OCA condition ratings of critical components. This research will develop a scalable methodology to model the probability of failure of components and systems that contribute to the performance of facilities in their respective FRM systems combined with consequences derived from hydrological models of the watershed to develop facility risk scores. This interim report documents the results of the first phase of this effort, stakeholder analysis and literature review, to identify candidate approaches to determine the probability of failure of a facility.

DISCLAIMER: The contents of this report are not to be used for advertising, publication, or promotional purposes. Citation of trade names does not constitute an official endorsement or approval of the use of such commercial products. All product names and trademarks cited are the property of their respective owners. The findings of this report are not to be construed as an official Department of the Army position unless so designated by other authorized documents. 


\section{Contents}

Abstract............................................................................................................................ if

Figures and Tables ................................................................................................... iv

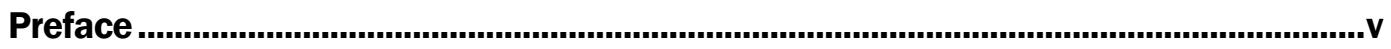

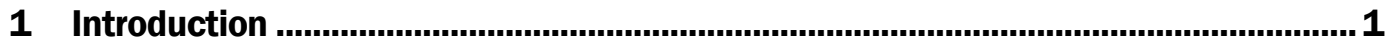

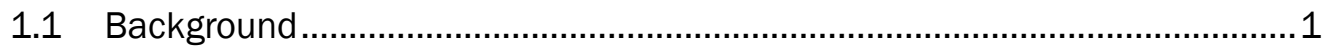

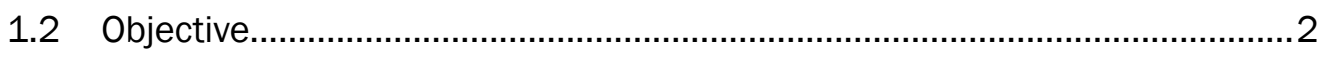

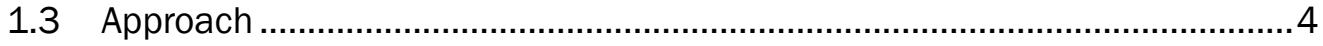

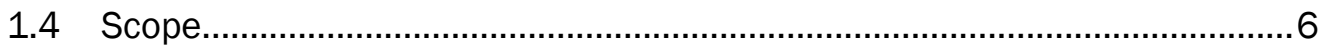

2 Background and Literature Review .................................................................. 7

2.1 Previous Flood Risk Management (FRM) safety analysis ............................ 7

2.2 Modeling complex socio-technical systems (STS) ......................................9

2.3 Modeling probability of failure (PoF) .......................................................10

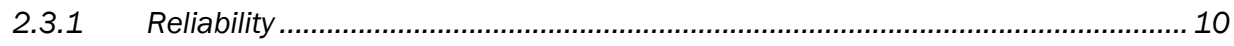

2.3.2 Bayesian methods ............................................................................. 11

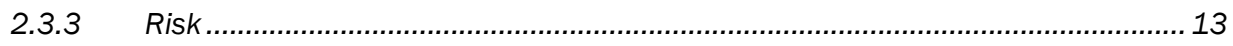

2.3.4 Resilience .................................................................................................. 13

2.4 Subject matter expert (SME) elicitation ......................................................

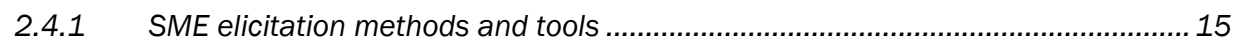

2.4.2 Successful SME elicitation ........................................................................ 15

2.4.3 Quantification of SME Input ........................................................................16

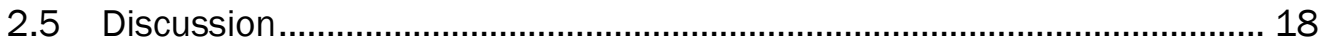

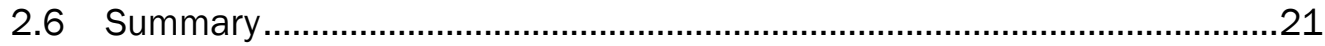

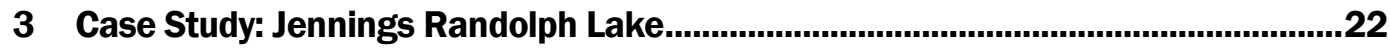

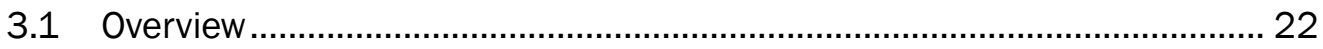

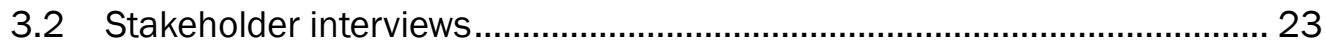

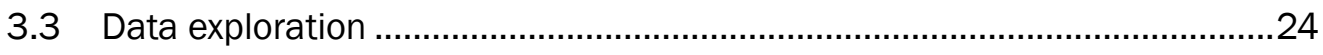

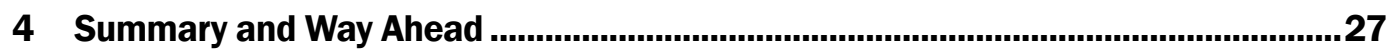

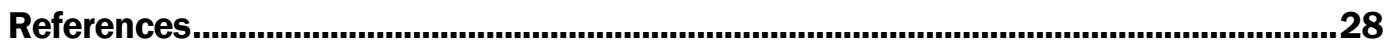

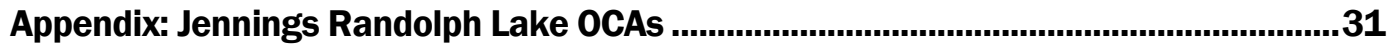

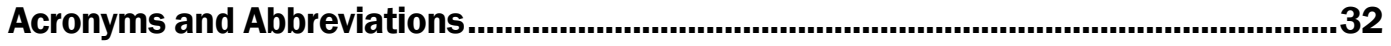

Report Documentation Page 


\section{Figures and Tables}

\section{Figures}

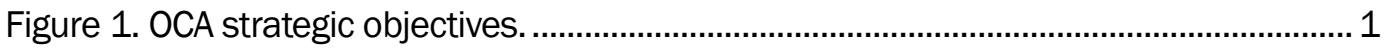

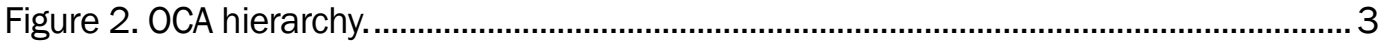

Figure 3. Decomposition of the "Determine Asset Risk" function........................................ 4

Figure 4. General approach for the execution of the project. ............................................ 5

Figure 5. Example Bayesian network of the systems and facility........................................19

Figure 6. Example Bayesian network of the components and a system. .........................19

Figure 7. Modeling Facility Operational Status. An example Bayesian network for facility operational status, where $\mathrm{C}$ represents components critical to the function of systems, S, that in turn determine the operational status of the facility, F.

Figure 8. North Potomac Watershed. Each circle represents a dam as documented in the National Inventory of Dams, with the orange circles representing dams on which an OCA is conducted. The bright orange circle in this figure is the Jennings Randolph Lake.

Figure 9. Systems associated with Jennings Randolph Lake in OCA hierarchy with expanded view of Bridges. Bridges consists of three sub-systems that each possess six OCA eligible components.

Figure 10. Jennings Randolph systems with expanded view of spillway gate systems. Spillway gate systems consist of a single sub-system, tainter-gate, with 24 OCA eligible components.

\section{Tables}

Table 1. FEM Asset Criticality Score descriptions

Table 2. Count of unique OCAs associated with each system for Jennings Randolph Lake. The count represents the sum of the OCAs present in the data set across all components associated with the system. 


\section{Preface}

This study was conducted for the Navigation Systems Research Program, Coastal Hydraulics Laboratory, US Army Engineer Research and Development Center, under Funding Account Code U4375151; AMSCO Code 031391. Ms. Morgan Johnston was the Program Manager for the Navigation Systems Research Program, and Mr. Peter Dodgion was the Program Manager for Asset Management, Headquarters, USACE.

The work was performed by the Institute for Systems Engineering Research (ISER) Branch, Computational Science and Engineering Division, Information Technology Laboratory (ITL), US Army Engineer Research and Development Center (ERDC) and the Hydrologic Systems Branch, Flood and Storm Protection Division, ERDC Coastal and Hydraulics Laboratory (CHL). At the time of publication of this report, Dr. Simon R. Goerger was ITL ISER Director; Dr. Jerry Ballard was ITL Computational Science and Engineering Division Chief; and Dr. Robert Wallace was the ERDC-ITL Technical Director for Engineered Resilient Systems. The Deputy Director of ERDC-ITL was Ms. Patti Duett, and the Director of ERDC-ITL was Dr. David Horner.

COL Teresa A. Schlosser was the Commander of ERDC, and the Director of ERDC was Dr. David W. Pittman. 


\section{Introduction}

\subsection{Background}

The US Army Corps of Engineers (USACE) operates, maintains, and manages more than $\$ 232$ billion worth of the Nation's water resource assets. Ensuring the proper functioning of these assets, particularly those associated with Flood Risk Management (FRM), impacts the lives of American citizens on a daily basis across the country. Operational Condition Assessments (OCAs) are performed on these assets' components at a minimum of every 5 years. The USACE requires an understanding of its current assessment process, and its effectiveness, in order to identify opportunities to improve the process through focused modernization efforts. This calls for a holistic review of the current OCA process and new processes to systematically develop a transparent, consistent, and traceable risk-based OCA framework. To achieve this vision of the OCA system, the following strategic objectives must be addressed:

1. Provide Access to Asset Data.

2. Enhance OCA Conduct and Quality.

3. Determine Asset Risk.

4. Develop OCA Prioritization and Scheduling Framework.

Figure 1 presents a high-level decomposition of these strategic objectives.

Figure 1. OCA strategic objectives.




The purpose of this document is to provide an overview of the result of initial stakeholder analysis and literature review of methodologies to identify the likelihood of failure of complex systems, in support of the strategic objective of determining Asset risk.

\subsection{Objective}

The objective of this project is to develop an enterprise framework for riskbased prioritization of OCA. Currently, OCAs are conducted each year without a risk-based prioritization method resulting in the expenditure of resources to assess assets that pose no risk to the enterprise. In particular, this project, scoped as a 3-year effort, will help decision makers understand which FRM facility components require an OCA based on their contribution to overall operational risk and current conditions. To improve understanding, the following terms and the OCA hierarchy diagram are defined for Figure 2:

- Facility - In the OCA hierarchy, "projects" are the highest level. For clarity, what is often called "project" in the OCA infrastructure hierarchy is called "facility" in this document.

- System - In the OCA hierarchy, "systems" are the next highest level. Two examples of FRM OCA systems are a "building" or a "spillway gate."

- Sub-system - In the OCA hierarchy, "sub-systems" give move specificity to the system level. For example, under the system "building," subsystems could be "maintenance building" or "administrative building." For the system "spillway gate," subsystems could include "tainter gate 1" and "tainter gate 2. "

- Component - In the OCA hierarchy, "components" are the lowest level and the level at which OCA ratings are given.

- FRM System - the network of FRM facilities associated with a particular watershed.

- Facility Failure - Due to rarity of facilities being non-operational, facility failure is defined as degraded operations (i.e., uncontrolled release of water from the FRM facility, which may or may not be catastrophic).

- System Failure - Similar to facility failure, system failure is defined as reduced capability to meet designed operational capacity.

- Component Failure - A component is considered to have failed when it has received an OCA score of B- or lower. A rating of B indicates that the component is performing its intended function and that any 
deficiencies are a result of normal wear. A rating of B- indicates that the component is beginning to show initial signs of the next lower level, and $\mathrm{B}$ - is the highest rating at which justification comments are required (USACE 2019).

Figure 2. OCA hierarchy.

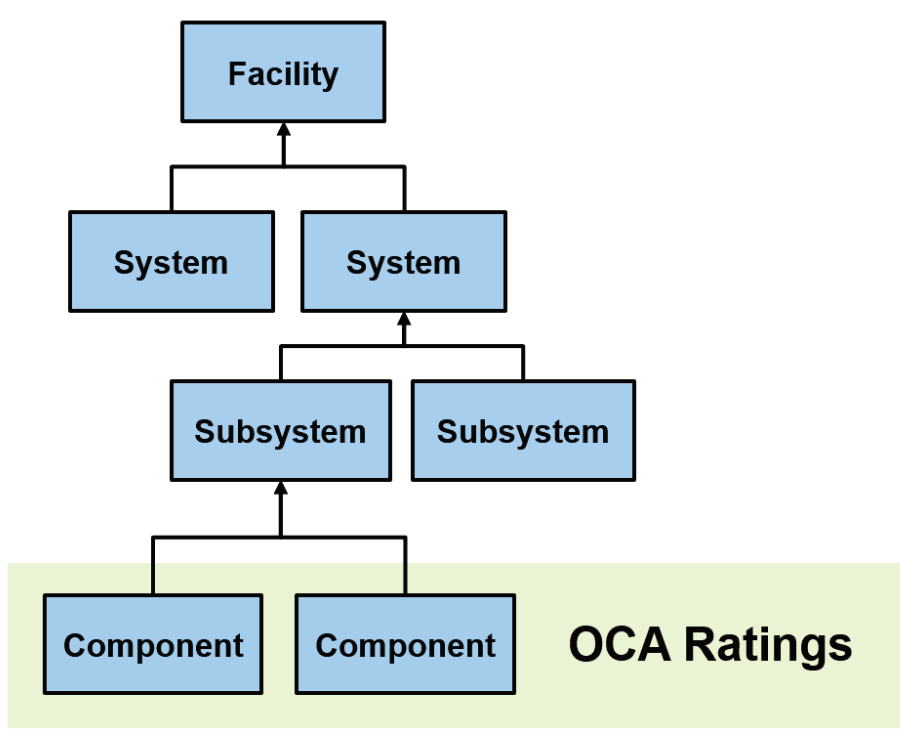

An enterprise risk-based prioritization framework for USACE asset management must be consistent, defensible, and feasible to implement at scale. The prioritization framework will rely on risk, determined by understanding the likelihood of a component failure at the facility level and the consequences of this failure in the context of the watershed FRM system. The number of components and their interactions in a single facility grow rapidly. Therefore, the methods developed for use in this framework must be capable of managing the computational challenges associated with large state spaces and incorporate the inherent uncertainty associated with the measurement of risk. Although this project focuses on facilities associated with FRM, the prioritization methodology developed should be generalizable to other business lines in the future. The output of the framework will be (1) the set of FRM facility components across the enterprise that should receive maintenance and OCA scheduling priority in order to maximize risk mitigation across the enterprise, (2) the uncertainty associated with model results, and (3) an easily understandable presentation of the potential trade-offs. Figure 3 decomposes the tasks associated with determining asset risk. 
Figure 3. Decomposition of the "Determine Asset Risk" function.

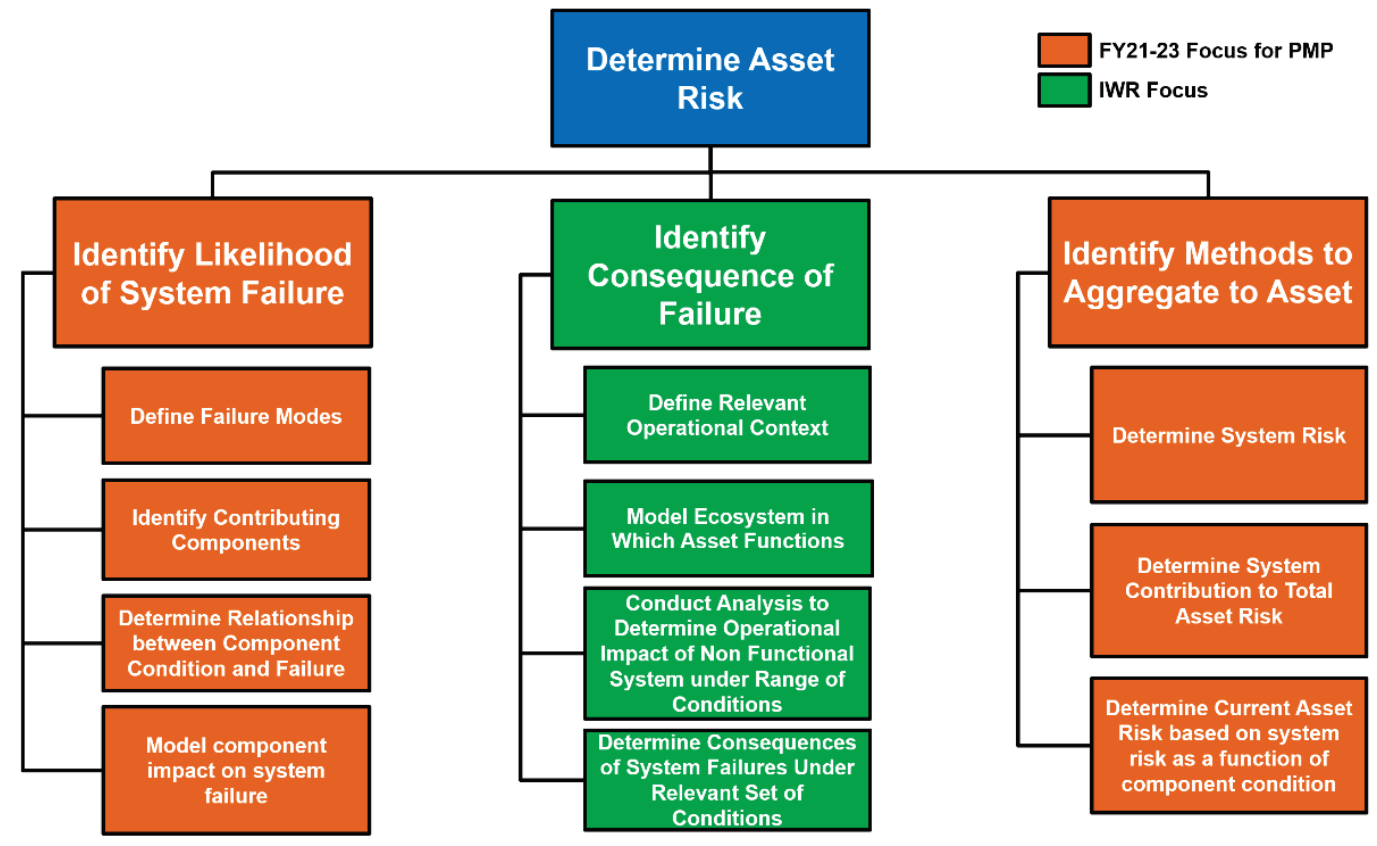

Initial Problem Focus. The initial problem that this research will address is the identification of candidate methodologies to determine the probability of failure of a facility based on the condition of components and their impact on the function of its systems and sub-systems.

\subsection{Approach}

The first element of this work is a literature review of methodologies to determine complex system probability of failure. The result of that literature is in Section 2. To implement the candidate methodologies, two case study watersheds have been identified. A key piece of determining probability of failure for flood risk management facilities in these watersheds is identifying and developing data. OCA and FEM data are available, but neither of these datasets has sufficient failure data, nor do they relay the relative importance of various systems/components as regards flood risk mitigation. To develop this data, the US Army Engineer Research and Development (ERDC) team is in the process of eliciting SME information from USACE district personnel and facility staff. Additionally, the ERDC team is collaborating with consequence modelers from the IWR. While the ERDC team is working to determine probability of failure, the IWR team is working to determine consequence of failure. These two teams have collaborated to identify appropriate case studies and are working to identify data integration requirements to determine risk. The 
result of this work will impact the use of investments and other actions to mitigate risk. The approach is illustrated in Figure 4.

Figure 4. General approach for the execution of the project.



The purpose of this interim report is to document the results of initial stakeholder analysis, data development for initial case study, and the initial literature review to inform the development of methodologies to address this challenge. This was accomplished through several avenues. The first was a focused literature review to clarify definitions of failure, reliability, and resilience to be used in this study. Additional literature review explored modeling complex socio-technical systems (STS), SME expert elicitation and judgement, which will be critical to the investigated potential solution methodologies. Second, two sets of stakeholder engagements were conducted with the FRM and Asset Management personnel and Operations personnel from the USACE Baltimore District and Jennings Randolph Lake facility, which provided insight into the execution of routine facility component inspections and their relation to the OCA and FEM data collection and integration. This led to further exploration of OCA and FEM data collection, structure, and utilization. The next section provides additional background and the results of the literature review. This is followed by the results of stakeholder interviews, a brief discussion of the data, and a summary. 


\subsection{Scope}

The following constraints, limitations, and assumptions serve to further focus the research during the first year.

Constraints

- Proof-of-concept application associated with Case Study 1 and 2 must be complete no later than 3OSEP21.

- Methodology initially focused on FRM but must be scalable to the enterprise and other business lines in future years.

- Must be feasible to integrate with consequence models from Institute for Water Resources (IWR).

\section{Limitations}

- Team has limited experience with USACE asset management.

- Team has limited travel authorization due to COVID-19 restrictions.

- Available data, OCA and Facilities and Equipment Maintenance (FEM), have inconsistencies and present challenges with matching data to components.

- Collection of new case study data requires cooperation and coordination from owners of case study facilities.

- Data on operational down time not readily available at component, system, or facility level.

\section{Assumptions}

- Assume that access to subject matter experts (SME) within USACE will be sufficient to inform problem and gain understanding of data.

- Assume that facility operators possess expertise to understand relationships between component and systems sufficient to identify critical components and their impact on system operations.

- Assume that facility operators possess expertise to understand relationship between systems and a facilities operational status. 


\section{Background and Literature Review}

As systems grow in complexity, understanding the interaction of the engineered system with the ecosystem in which it sits and the humans that operate and maintain it can become challenging. Operational models of these STSs can aide decision makers in understanding how the components of the system influence the system's performance and elements of the system beyond the control of the system operators, such as the environment, and the performance of human operators themselves, affect system outcomes.

This literature review will provide an understanding of the current state of the art in modeling complex STSs with the goal of identifying methods to determine the probability of failure of a facility operated and maintained by the US Army Corps of Engineers FRM business line. This section will briefly examine previous work related to flood risk management facility, dam systems, and gate failures; recent approaches to modeling complex STSs; and SME elicitation.

The focus of this literature review is to understand opportunities to leverage state-of-the-art complex systems modeling to represent USACE facilities. This will inform how populating this modeling framework with data from existing or future data sources will be achieved. Much of the discussion in this review will focus on dams as an example facility, but the intent is to identify methods that might be applicable across facility types.

\subsection{Previous Flood Risk Management (FRM) safety analysis}

Gates, one of the most critical dam systems, consist of components that are assessed by teams of experts to determine their condition (Lewin et al. 2003). This assessment is separate and distinct from any maintenance action initiated by the dedicated staff that operates and maintains the gate. The OCA process informs decisions that impact a number of non-routine maintenance actions following its completion.

USACE has previously taken strides towards quantitative risk assessment at the enterprise and Major Subordinate Command levels. The following is by no means an exhaustive account, but the following provides some guidance on previous approaches. Lewin et al. (2003) provide a summary of preliminary gate reliability assessments and risk assessments of five USACE 
Huntington District dams. Of the 18 gates tested, 3 did not operate properly. They also conducted a preliminary fault tree analysis and found that in ideal conditions, spillway gate probability of failure on demand was 1 in 10 . The primary contributors to failures were control system failure (50\%), brake release failure (25\%), and miscellaneous mechanical problems (25\%). They did not consider human operational factors or the possibility of main power supply failure. Others have noted that human factors, such as maintenancerelated issues, human error in operation, and lack of back-up power supply could actually dominate the root causes for spillway gate failure (Dam Safety Committee 2010; DeNeale et al. 2019).

Lewin et al. (2003) and Dam Safety Committee (2010) note that in determining the impact of spillway gate reliability on dam probability of failure, the number of redundant gates and the maximum flood storage to maximum discharge capacity ratio must be considered. As the number of redundant gates increases, the impact of any individual gate failure on overall dam probability of failure is decreased. Also, as the maximum flood storage to maximum discharge capacity ratio increases, the impact of gate failure on overall dam probability of failure decreases because dam functioning depends relatively less on water discharge than water storage. A key insight from this work is the uniqueness associated with each facility. Although like-type facilities share common systems and components, their configuration and importance to the functioning of the facility might vary significantly based on local conditions.

Previous work related to flood risk management facility safety highlights the need to include the condition of the operational staff and a consideration for local conditions when developing an enterprise framework. When considering the operational staff, factors such as experience, manning levels, and shift schedules contribute to the likelihood of a human error occurring. These errors might manifest themselves during routine maintenance or control events with delayed or immediate consequences to the operation of the facility.

Local conditions play an important role in the design and configuration of facilities. This contributes to the challenges associated with developing a model that scales to the enterprise. Each facility's unique operational mission that it was designed to address must be considered when determining how each system, subsystem, or component contributes to the overall functioning of the facility. This is most appropriately informed 
by experts on the facility and how it interacts with its environment to perform its mission.

\subsection{Modeling complex socio-technical systems (STS)}

STSs, a class of complex adaptive systems, refer to complex systems formed by the interaction between technological systems and their human designers, operators, and maintainers (Dam et al. 2013). Socio-ecological systems and the more recently proposed socio-technical ecological system include the environment within the system boundary, with the latter seeking to recognize the need for the consideration of the environment and technology for a truly holistic understanding of the system under study (Ahlborg et al. 2019). While infrastructure resilience is often viewed through the lens of STS, many resilience directives do not address the human element, the operators and maintainers, which play key decisionmaking roles in these complex socio-technical systems and often do not account for the interplay between man-made system and the environment and the stresses produced by these interactions (Thomas et al. 2019). The volume of data generated in the modern era presents opportunities for a data-informed understanding of the state of these systems, but absent a modeling construct to aide in identifying key vulnerabilities, anticipating surprise, this is not sufficient (Eisenberg et al. 2019). The development and curation of holistic operational models that make appropriate use of empirical data to inform understanding and decision-making is key to improving the resilience of critical infrastructure (Alderson et al. 2015). Many modeling frameworks are used in this area including agent-based models, systems dynamics models, and network models, to name a few. Extending these frameworks to incorporate human decision makers and the environment is an active research area.

Focusing on the case study flood risk management facility, the key question to address with the model is the likelihood that the gate will perform as expected given a set of inputs on the state of the other components of the system. Once a high-level conceptual model of the complex STS is specified, approaches must be developed to model the relationships between components and the operation of the gate. Dependencies could exist between components, but for the sake of simplicity, assume that the inputs are independent. Modeling decisions regarding which components to represent within the framework and appropriate sources of data to populate modeling frameworks are some of the challenges that must be addressed once the conceptual model is 
specified. In this case, the key aspect under study is the probability of failure of the gate as a function of the condition of its components.

The IWR team is using the USACE Corps Water Management System (CWMS) tool to develop consequence of failure data for the flood risk management facilities in the identified case study watersheds. CWMS is a software suite supporting the USACE water management mission. The pertinent piece of that software is that it provides consequence/damage analysis in terms of monetary damages and life loss based on a range of environmental conditions. The two teams will integrate probability of failure $(\mathrm{PoF})$ data with consequence of failure data to determine risk.

$$
\text { Risk }=\text { PoF } \mid \text { Component Condition } \times \text { CoF } \mid \text { Environmental Hazard }
$$

\subsection{Modeling probability of failure (PoF)}

A holistic, systematic approach to flood risk management facility safety risk assessment is necessary because mere qualitative judgment is not a reliable measure. A quantitative approach to risk assessment is critical in reducing risk and increasing confidence that gates will operate reliably (Dam Safety Committee 2010). A critical piece of this work is quantifying PoF. In some cases, the probability that a component of a system will fail can be determined from empirical data or estimates of like type systems. When examining fleet problems, it is possible to obtain data to directly estimate the mean time to failure for components or other similar measures. In complex systems, this is often more challenging due to the custom nature of the system. Key functions within the engineered system might be filled by different components that are configured in a different manner within each system. In many complex real-world STSs data on the failure of components in their operational setting can be challenging to obtain or if obtainable is of insufficient quantity to employ standard methods reliably.

\subsubsection{Reliability}

Determining the reliability of the components and systems is critical to the understanding of risk for FRM facilities. System reliability can be defined as the probability that a system will perform its intended function for a specified period of time under stated conditions (Yontay 2016). Since an FRM facility is a complex network comprised of many interconnected components, system reliability analysis is required to identify the critical 
components and make decisions regarding inspection, repair, and replacement to minimize the risk of system failure (Tien and Der Kiureghian 2016). Further, reliability analysis is a method to determine the probability of failure (Mahmoodian et al. 2017). The Dam Safety Committee of New South Wales published a study on the reliability of spillway flow control systems that links reliability and risk assessment processes to identify critical components, weaknesses in systems, and maintenance programs. To link to risk, they also highlight that the reliability assessment should be linked to the overall risk profile of the dam, including both upstream and downstream effects of gate operation. Finally, they express reliability as the confidence that a component will operate as planned (Dam Safety Committee 2010).

The infrequent nature of component and system failure of FRM facilities as well as the reliance on SME input (Lewin et al. 2003) lends well to use of Bayesian methods to conduct reliability analysis. They can be used to estimate reliability when no failures have been observed or where there is no observed data (Wilson and Fronczyk 2016) and can represent system failure in a probabilistic way to account for uncertainty and ambiguity (Salem et al. 2006). Finally, Bayesian networks can be used to explain the propagation of failures, introduce factors of common causes, the dependencies between events, and incorporate maintenance actions, making it possible to model knowledge on the reliability of a system whatever its complexity is (Simon et al. 2007).

\subsubsection{Bayesian methods}

The use of Bayesian methods to understand the performance of systems based on limited empirical data and SME input is well justified in the literature (Wilson and Fronczyk 2016). A compelling feature of these methods is their ability to accommodate data of varying types along with their ability to update the model as new data becomes available. The foundation of these methods is Bayes rule,

$$
P(A \mid B)=\frac{P(B \mid A) P(A)}{P(B)}
$$

which presents that given two events, A and B, the determination can be made that the probability that A will occur (or be true) given that $\mathrm{B}$ has occurred (or is true) if there is an understanding of the probability of $B$ occurring given A and the probability that event $\mathrm{A}$ and $\mathrm{B}$ occur 
independently. The belief about the probability of A prior to knowing anything about $\mathrm{B}$ is referred to as the prior probability, $\mathrm{P}(\mathrm{A})$. The probability of $A$ given $\mathrm{B}, \mathrm{P}(\mathrm{A} \mid \mathrm{B})$, is referred to as the posterior. The probability that $\mathrm{B}$ occurs given $\mathrm{A}$ is the likelihood (Russell and Norvig 2010).

In particular, Bayesian networks provide a graphical framework for representing the relationship between variables in a transparent manner easily understood by human experts (Koller and Friedman 2009). Bayesian networks are directed acyclic graphs whose nodes represent random variables and the arrows represent probabilistic dependencies between these random variables (Scutari 2019). These representations also facilitate inference around the phenomena of interest and can allow for updating as new data arrives or for learning of the network structure from data if available. In the absence of data, SMEs can specify the features of a Bayesian network based on their theoretical or conceptual model (Jacob et al. 2011). Multiple software packages exist to assist in the application of Bayesian networks (such as Netica, BayesiaLabs), and opensource communities have several packages that facilitate the use of Bayesian methods (R, Python).

While there are many challenges inherent to the use of Bayesian networks for modeling, two specific challenges present themselves to this research: computational limitations and determination of characteristics that impact system resilience.

To overcome some of the challenges associated with the application of Bayesian networks, practitioners have turned to novel, compression algorithms (Tien and Der Kiureghian 2016). As with any modeling framework, incomplete and insufficient data represent another limitation in the use of Bayesian network (Nunes et al. 2018; Yontay 2016). A lack of data limits the ability to define Bayesian networks probability tables and requires elicitation of relevant data from SMEs to manually define the tables (Uusitalo 2007).

System characteristics represent the other major implementation challenge for Bayesian networks. In the event that system data are incomplete or insufficient, SME knowledge must be elicited to rectify the situation. Access to relevant SMEs may be limited or non-existent. As such, identification and characterization of key sub-systems or 
components will be impacted. This, in turn, limits the ability of the model to quantitatively or qualitatively define infrastructure resilience.

\subsubsection{Risk}

Risk assessment is a critical activity for USACE flood risk management facilities as failure of facilities can have significant negative economic, life, health, and/or safety impacts. USACE defines risk assessment as "defining the nature of the risk, its probability, and the consequences, either quantitatively or qualitatively (or a combination)" with the goal to identify, describe, examine, and evaluate risks and their potential impacts to provide risk managers with the information needed to inform decisions (USACE, n.d.).

USACE further describes risk assessment as a "systematic, evidence based approach for quantifying and describing the nature, likelihood, and magnitude of risk associated with the current condition and the same values resulting from a changed condition due to some action" (USACE, n.d.).

This study focuses on the probability variable of this equation by seeking to determine the PoF for critical components of dams and flood risk management facilities based on OCA and FEM data. The IWR is examining the consequence of failure variable in the equation. The goal is to eventually pull these into a generalizable risk-based framework to support resource allocation decision making.

\subsubsection{Resilience}

A failure of an FRM facility or any of its systems or components would constitute a shock or disruption for which the facility will want to build resilience. Resilience is defined by the National Infrastructure Advisory Council as endogenous and exogenous characteristics of infrastructure that impact the capability to assess strategic and/or operational risk of an asset (NIAC 2009). Similarly, Vugrin et al. (2011) and Hossain et al. (2019a) recommend the determination of absorptive, adaptive, and restorative capacity to assess infrastructure resiliency. The qualitative or quantitative determination of these capacities would give insight into the potential strategic and/or operation risks associated with a particular piece of infrastructure (or type of infrastructure asset). 
Once quantified, the impact (I) of a particular event to the performance of a given infrastructure asset can be calculated as a function of the difference between the expected performance $(E P)$ and actual performance $(A P)$ over time. That is,

$$
I=\int_{t_{0}}^{t_{f}} E P(t)-A P(t) d t
$$

It is problematic, however, to be able to determine the characteristics that contribute to the absorptive, adaptive, and restorative capacity for a given piece of infrastructure since infrastructure assets of the same type can be implemented in vastly different ways.

One method that has been developed is the use of a Bayesian network that demonstrates all the causal relationships among the different qualitative and quantitative variables and allows practitioners to understand the interdependencies among the variables and how the change in one variable affects the others. This method can be applied to determine the resilience capacity, which quantifies the capability of a system to absorb, adapt, and recover from any shock or disruption (Hossain et al. 2019a). This may be an area for further development in terms of identifying the restorative and adaptive capacity of flood risk management facilities.

\subsection{Subject matter expert (SME) elicitation}

SME elicitation provides a means for obtaining expert judgment when objective empirical data are not available due to the nature of the study, costs, or other factors. The elicited data are generally subjective in nature and require expressing it in a statistically useful form (Marks et al. 2013).

Expert elicitation has proven especially useful within safety-critical industries when operational data are not available to provide quantitative measures suitable for inclusion in probabilistic risk models. These models ensure optimal safety of systems by identifying and minimizing risks. This expert elicitation for the purpose of supporting risk assessment involves two components: (1) an SME and (2) a judgment about the likelihood of event occurrence. The success of expert elicitation hinges on the wellorchestrated interplay of the right SME using the right information (or the information available) in conjunction with the correct method to judge event likelihoods (Boring 2007). 


\subsubsection{SME elicitation methods and tools}

There are several methods through which to collect SME input as described below by Hickey and Davis (Hickey and Davis 2003).

Collaborative Sessions. Gathering multiple stakeholders in a single room to conduct a collaborative session.

Interviewing. Primarily used to surface new information or to uncover conflicts or politics.

Team Building. A second-order elicitation technique in that it does not directly surface requirements. Instead, it is any of a wide variety of synthetic group experiences that help build communication and mutual trust among the stakeholders so that later first-order elicitation techniques become more effective.

Questionnaires or Surveys. Best used for problems that are fairly concrete or as an aid in understanding external customer needs.

Models. A means to (a) facilitate communication, (b) uncover missing information, (c) organize information gathered from other elicitation techniques, and (d) uncover inconsistencies.

Delphi Method. Typically consists of three to six rounds of SME elicitation with qualitative and quantitative assessment from the previous round used to prepare the subsequent round. This method was developed by the Research and Development (RAND) Corporation for the "systemic solicitation and collation of judgements on a particular topic through a set of sequential questionnaires interspersed with summarized information and feedback of opinions derived from earlier responses" (Balasubramanian and Agarwal 2012). It is useful when evidence is lacking or limited; it relies on "collective intelligence" of group members to jointly produce better results than anyone in the group could produce on his or her own, resulting in increased content validity (Miller et al. 2020), and it works well when there is a limited number of SMEs available to provide input.

\subsubsection{Successful SME elicitation}

Whichever method is selected, successful elicitation depends on identifying the objectives and data requirements, building good elicitation 
questions, selecting the appropriate experts, and preventing elicitation and modeling bias. This is done through detailed planning, preparation, and execution of the elicitation technique. Additionally, the elicitation should be designed to fit the experts rather than forcing the experts to adapt to the analyst's methods while generating data required to address specific study objectives (Teter 2014).

SME elicitation should control, to the extent possible, for factors that can enter into the elicitation and influence the experts' responses. These potential sources of errors include the following (Marks et al. 2013):

1. Elicitation bias (the data collected during elicitation do not accurately conform with the real world phenomena the analyst is attempting to quantify) due to either motivational (an expert does not report his true judgment in his responses) or cognitive (when an expert's judgment does not accurately represent the quantities of interest to the analysts) bias of the experts.

2. Modeling bias (using flawed or otherwise inappropriate methods of employing the SME-elicited data into the analysis cognitive) due to either tool (use an inappropriate statistical method for incorporating the SME data into the analysis) or training (when the analysts misrepresent or inaccurately characterize when they encode the expert responses into data) bias.

After successful SME elicitation, to include controlling for bias, the information gathered must be quantified to utilize it for analysis.

\subsubsection{Quantification of SME Input}

There are several methods that may be used to quantify the SME data.

\subsubsection{Structured Expert Judgment (Christophersen et al. 2018).}

Christophersen et al. (2018) give a good summary of quantifying SME input through structured expert judgment, which is the process of eliciting expert knowledge as a form of scientific data and consists of a variety of expert elicitation protocols. They summarize the two main ways in which experts' judgments are aggregated either behaviorally (striving for consensus via discussion and deliberation), or mathematically, involving independent individual expert estimates being combined with a given 
mathematical rule. The mathematical methods typically use either an equal weighting or a weighted linear combination of opinions.

Christophersen et al. (2018) determined that it is challenging to find calibration questions that closely match the types of questions needed to elicit conditional probabilities for a Bayesian network, especially if there are no analogs from real-life observations. Instead, they adopted a consensus-based expert scoring scheme and an innovative expert elicitation method that uses a structured and iterative process for developing consensus, similar to the Delphi Method. In this process, expert opinion is weighted on the basis of mutual recognition among experts expressed through a regularly repeated blind procedure where they asked the SME to select monitoring parameters and relative critical thresholds at each node of the event tree, instead of being asked directly for probabilities. In this way, the individual and collective specialist knowledge is more effectively exploited, since the experts are asked to discuss and express themselves directly in their field of expertise; their knowledge enters the statistical model without the filter of personal sensitivity to probabilities (Christophersen et al. 2018).

\subsubsection{Scaling (Boring 2007)}

Boring (2007) notes that failure estimation entails comparison either to a standard or to other tasks or errors that the analysts review and identifies psychological scaling as the method to ensure a stable, repeatable process for comparison. His summary of the five common methods of psychological scaling is the following:

1. Scaling by paired comparison. In this method, all possible pairs of events are presented to the analyst. The analyst then judges for each event pair which event is more likely to occur. This method provides the frequency that a given event is more likely to occur than another event.

2. Scaling by ranking. In this method, the analyst assigns a rank order or event likelihood to each event, resulting in a rank ordering all event likelihoods.

3. Scaling by sorting. This method, also known as card sorting, entails sorting events into piles based on their similarity. In terms of failure estimation, the piles can be sorted to represent different categories of event likelihood. 
4. Scaling by rating. This method, also known as categorical judgment or Thurstonian scaling, entails assigning an event to a category label or number that reflects the event likelihood. This method has the advantage that an event may be analyzed in isolation, without the need for a comparative listing of events.

5. Scaling by fractionation. This method is also known as magnitude estimation or direct estimation. In this method, the analyst assigns a number or similar descriptor to the event to indicate the event likelihood. Like scaling by rating, this method allows the analyst to look at a single event without the need for comparing other events. This method features a further advantage in that the resulting scale is a continuous scale instead of a categorical scale and scaling by fractionation is the most powerful method available for expert elicitation, although it is susceptible to scaling biases. "Bias" means the fact that people do not treat a scale in a consistent, linear fashion.

\subsubsection{Bayesian methods}

Bayesian methods can be useful in the quantification and modeling of the results of SME elicitation. If using Bayesian statistical methods, it is recommended that sensitivity analyses be conducted on any a priori distribution assumptions made to support the analysis (Teter 2014).

Because of the lack of FRM facility failure data, SME elicitation will be a critical component of this project moving forward. The selection and implementation of the appropriate elicitation technique and data quantification will be crucial to building and testing the integration of OCA and FEM data into decision-making models. The differences between systems and components across the enterprise at each facility will also be a significant challenge that will need to be addressed through the SME elicitation and data quantification process.

\subsection{Discussion}

Figure 5 presents an example Bayesian network modeling the probability that a facility ( $F$ ) functions given the state of its systems, $S \mathrm{i}$, where $\mathrm{i}=1 \ldots \mathrm{n}$ and $\mathrm{n}$ is the number of systems critical to the functioning of the facility, $P\left(F \mid S_{1}, S_{2}, \ldots, S_{n}\right)$. 
Figure 5. Example Bayesian network of the systems and facility.

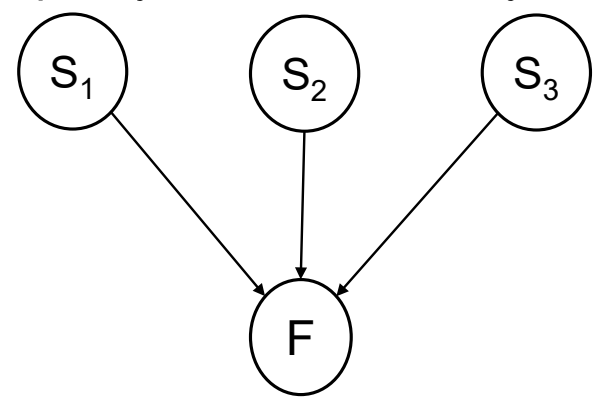

In this case, the variables at the facility and system level have only two states, fully operational or degraded. Figure 6 presents an example Bayesian network modeling the probability that a system functions given thestate of its components, $\mathrm{C}_{\mathrm{j}}$, where $\mathrm{j}=1$...m and $\mathrm{m}$ is the number of components critical to the proper functioning of the system, $P\left(S_{i} \mid C_{1}, C_{2}, \ldots, C_{m}\right)$.

Figure 6. Example Bayesian network of the components and a system.

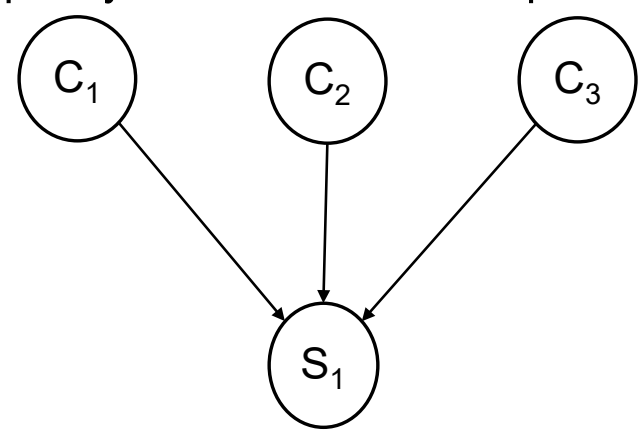

The state of critical components is determined by observation of the component during its most recent OCA. This assessment can take on values $\mathrm{A}$ through $\mathrm{F}$, but the state space can also be reduced to a simple Pass or Fail where an OCA rating of A, A-, B+, or B are a Pass with anything less than a B being a Fail.

Figure 7 presents these two models combined to provide a more complete model of the system. 
Figure 7. Modeling Facility Operational Status. An example Bayesian network for facility operational status, where $\mathrm{C}$ represents components critical to the function of systems, S, that in turn determine the operational status of the facility, $\mathrm{F}$.



With sufficient number of failure events, in this case the number of times a system experienced degraded operations when each component was in a degraded state, an estimate of $P\left(S_{i} \mid C_{1}, C_{2}, \ldots, C_{m}\right)$ might be determined from data, but when the number of recorded system failures is small or does not exist, this can become challenging. The same challenge exists when trying to estimate $P\left(F \mid S_{1}, S_{2}, \ldots, S_{n}\right)$. Knowledge from SMEs must be elicited in such situations.

To make use of this model for inference about the state of the facility, one needs to populate, from data or SME input, the conditional probability tables associated with each level.

For each component, existing OCA data to understand the state of each component can be leveraged, but one does not possess empirical data that informs the relationship between the state of the component and the state of the system. Given that these are engineered systems, there is potential to inform this through an examination of engineering specifications augmented by expert judgement. This is also the case when understanding how the state of the system impacts the operational status of the facility. Operationalizing a data collection plan to provide data on the operational status of systems and facilities would alleviate some of the need for expert judgement, replacing expert judgement with observational data as they are collected. 
At the system level, it might be reasonable to assume that a system is nonoperational if it has a non-routine maintenance request in the system. In this manner, it might be possible to populate the conditional probability tables required at the system level using OCA and maintenance data.

An alternative approach at the system level might be to define the random variable $S$ as the state of the system over some finite time horizon. Using this approach, one might leverage the age of components and their mean time to failure to understand if a component is expected to fail in the given time horizon. The component's impact on the system would still need to rely on expert judgement most likely to understand its impact on the system's operation or the previous assumption regarding non-routine maintenance could be reasonable.

At the facility level, SME judgement combined with engineering specifications regarding a system's contribution to the facility's operation will be required. Note that here, the definition of the facility's operational state might bear some discussion. Since these facilities are seldom totally non-operational, the state space might need to be adjusted to fully operational or degraded.

\subsection{Summary}

While multiple modeling approaches possess the potential to be applied to this problem, a model based on Bayesian approaches seem most reasonable given the objectives. Bayesian networks provide a means of incorporating both quantitative and qualitative data while providing an intuitive means of communicating with stakeholders about the problem. During the next phase of the project, the team will develop a proof of concept model in support of the first case study leveraging OCA data, FEM data, and SME input from the Jennings Randolph Lake operators. This case study is discussed in greater detail in the next section. 


\section{Case Study: Jennings Randolph Lake}

This section provides an overview of the Jennings Randolph Lake, the first case study selected for this work, the results of initial stakeholder interviews with the operating staff, and the result of initial data exploration.

\subsection{Overview}

The Jennings Randolph Lake provides a first case study in the application of these methods, and it is useful to begin to populate this framework using existing data to inform further discussion. Figure 8 presents the Jennings Randolph Dam in the context of the North Potomac Watershed.

Figure 8. North Potomac Watershed. Each circle represents a dam as documented in the National Inventory of Dams, with the orange circles representing dams on which an OCA is conducted. The bright orange circle in this figure is the Jennings Randolph Lake.

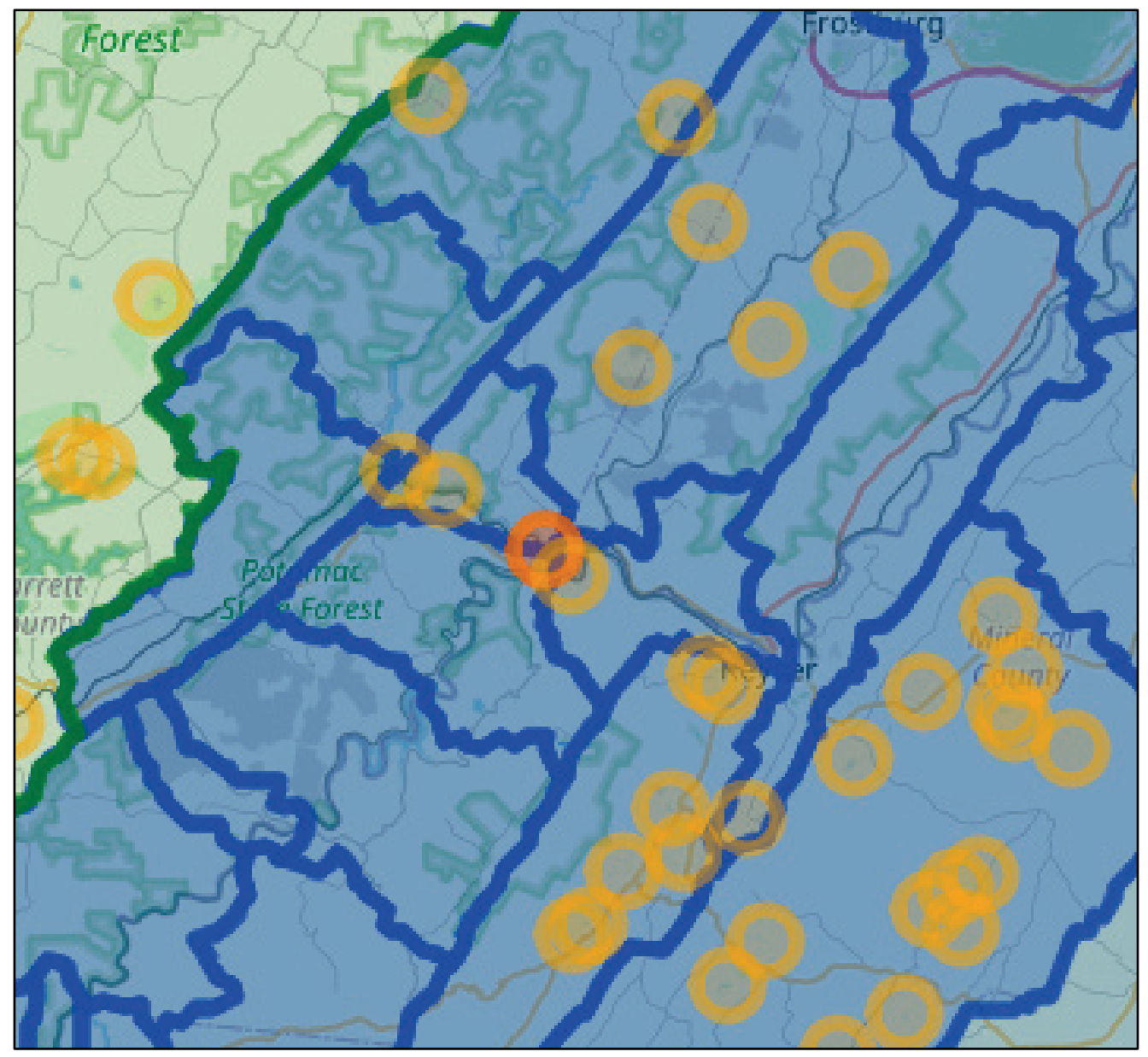




\subsection{Stakeholder interviews}

Two sets of stakeholder interviews were conducted with the FRM and Asset Management personnel and Operations personnel from the USACE Baltimore District and Jennings Randolph Lake facility to learn about their facility, inspections, and data, as well as to get stakeholder buy-in. These interviews provided insight into the execution of routine facility component inspections and their relation to the OCA and FEM data collection and integration.

Key findings include the fact that the OCA and FEM databases have different component hierarchies. Routine inspections are conducted for facility maintenance but only entered into the FEM database if a work order is required. The district conducts an annual review of the OCA database.

The engagements also highlighted the challenges in creating a generalizable solution across the enterprise due to subjective assessment of criticality scores. This appears to be because not all facilities contain the same components; the nature of defining failure at the component and system levels is imprecise; and each facility has some authority over hierarchy specifics and nomenclature for its OCA and FEM databases.

Further complicating the current situation is that the OCA and FEM databases have no points of interaction/connection/integration. The stakeholder engagements were very enlightening as the current status of implementation and utilization of the OCA and FEM databases at the district and facility levels and challenges to integrating and utilizing them at the enterprise level. The FEM criticality scores will prove useful because they provide a measure of the relative criticality of each component as regards facility operation. However, the team will need to discuss these further with the facility staff to understand how these scores were generated. Table 1 shows the Asset Criticality Score descriptions. 
Table 1. FEM Asset Criticality Score descriptions.

\begin{tabular}{|c|l|}
\hline Value & Description \\
\hline 1 & Failure will NOT result in impact/inconvenience in providing service/authorized function. \\
\hline 2 & Failure increases cost to the Government in providing service/authorized function. \\
\hline 3 & Failure may result in impacts/inconvenience in providing service/authorized function. \\
\hline 4 & Failure will result in modest impacts/inconvenience in providing service/authorized function. \\
\hline 5 & Failure will result in significant impacts/inconvenience in providing service/authorized function. \\
\hline 6 & Failure will result in an unscheduled modest loss of service/authorized function. \\
\hline 7 & Failure causes an unscheduled significant loss of service/authorized function. \\
\hline 8 & Failure causes loss of service/authorized function or impacts public health/safety/environment. \\
\hline 9 & Failure causes loss of service/authorized function, legal violation, or life safety risk mitigation. \\
\hline 10 & Failure expected to result in the loss of life under normal conditions. \\
\hline
\end{tabular}

\subsection{Data exploration}

Data on the operational condition of assets such as the Jennings Randolph Lake are captured through the conduct of OCA. The results of the OCA are entered into a database by the asset or facility owner and viewed by USACE leadership. Each facility is represented in the OCA database with a hierarchy that decomposes the facility to its constituent parts with the lowest level, the component being the target for condition assessment. Jennings Randolph Lake decomposes into 17 unique major systems, with unique 76 sub-systems, and 175 unique components types. Note that in the data that the team examined, in some cases, systems map directly to components.

The 17 unique major systems that compose Jennings Randolph Lake are shown in Figure 9. These major systems decompose to sub-systems or components. Bridges, for example, maps to three sub-systems with six components per sub-system. A full breakdown of the OCAs conducted per system is in the Appendix (Table 2). 
Figure 9. Systems associated with Jennings Randolph Lake in OCA hierarchy with expanded view of Bridges. Bridges consists of three sub-systems that each possess six OCA eligible components.

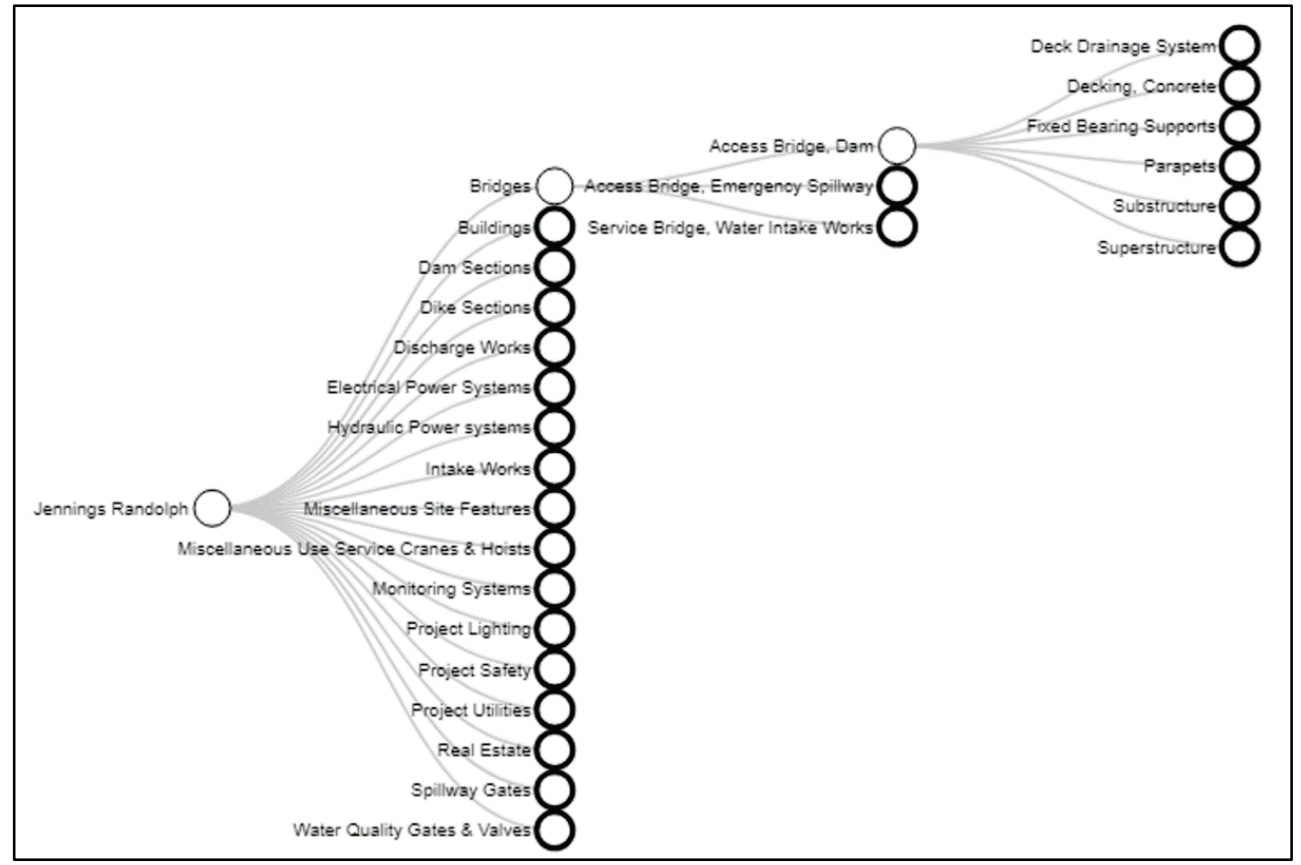

By contrast, Figure 10 shows that Spillway Gates maps to only a single sub-system, a tainter-gate, which consists of 24 components.

Figure 10. Jennings Randolph systems with expanded view of spillway gate systems. Spillway gate systems consist of a single sub-system, tainter-gate, with 24 OCA eligible components.

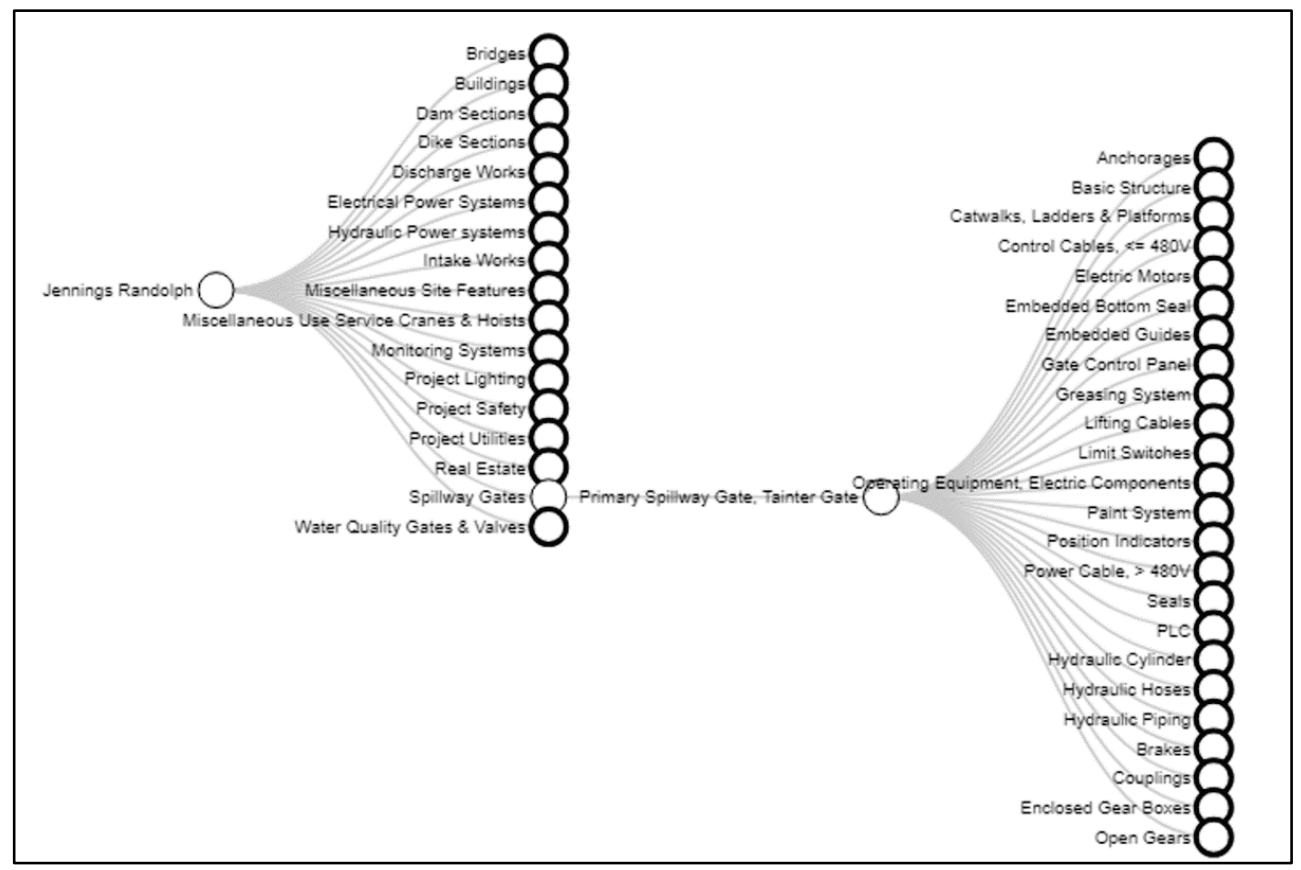


While each component is important to the functioning of the system, a degraded condition of some components will likely require more urgent attention than others to ensure that the sub-system, system, and facility do not experience degraded operations. SME input will be required to understand the relative contributions and importance of each component, system, or sub-system to the functioning of the facility.

In addition to OCA data, the USACE maintenance tracking system, FEM, contains a similar hierarchy along with maintenance actions. Each component in FEM receives a criticality score, 1-10, determined by facility leadership that indicates the likely impact of the component's failure on the facility's operation. These scores, or a similar construct, possess the potential to assist in managing the complexity of the problem. Once this structure is configured, this structure possesses the potential to be used for inference as new OCA ratings on components are obtained. Work is ongoing to explore the mapping of this criticality score from FEM components to OCA components.

Data describing when a facility, system, or sub-system is operating under degraded conditions has been challenging to identify. FEM data possess some potential to inform this discussion. Should this be obtained, and assuming it can be associated with the OCA component ratings, it might enable options to populate this model using observational data. This might then be compared to the SME-generated models or used to update the conditional probability tables associated with each level of the model. Important to this in either case will be an agreed-upon definition of degraded operating conditions. For instance, in the absence of data, one might pose the question as "What is the probability that this facility will operate under degraded conditions within the next 90 days?" where degraded conditions are defined as the occurrence of a non-standard maintenance event of a critical system, scheduled or un-scheduled. 


\section{Summary and Way Ahead}

Modeling the performance of complex facilities with multiple systems, each with many components, requires a flexible and scalable modeling approach that can account for the use of both quantitative and qualitative data. In the absence of empirical failure data, developing an appropriate conceptual model of a facility and its unique configuration of systems and components will require the input of stakeholders from the facility under study regardless of modeling approach. OCA data and FEM data provide the two primary sources of component and system assessment and maintenance data to develop the conceptual model of the facility, the condition of its components, and to determine events that occur at the facility over time, but challenges exist in integrating these two data sources. Some key outcomes of this phase are the following:

- Modeling Methodology. This research identified Bayesian networks as one reasonable modeling approach that could be employed given the complexity of each facility and the available data. These methods have been successfully employed in similar settings (e.g., Cavalieri et al. 2017). One particularly appealing characteristic of this method is the ability to update these models with empirical data if and when they becomes available. This potentially allows these methods to be employed given the as-is state of the OCA system and bridge over to a to-be state that provides access to additional data sources.

- Case Study 1. In collaboration with the IWR, the team identified the North Potomac River sub-basin as the first case study. This section contains one USACE facility: Jennings Randolph Lake. The team achieved buy-in for participation from the stakeholders at the facility and have follow-up sessions scheduled next quarter with the facility operators to elicit data required to inform the modeling effort.

- Case Study 2. In collaboration with the IWR, the team identified the Trinity River sub-basin as the second case study. This section of the watershed contains three USACE facilities: Ray Roberts Lake, Lewisville Lake, and Grapevine Lake. These facilities have high-quality OCA data, FEM data, and CWMS models. Also, the team has connections with Fort Worth District personnel to facilitate further data gathering and facility understanding. 


\section{References}

Ahlborg, H., I. Ruiz-Mercado, S. Molander, and O. Masera. 2019. "Bringing Technology into Social-Ecological Systems Research-Motivations for a Socio-TechnicalEcological Systems Approach.” Sustainability 11(7). https://doi.org/10.3390/su11072009

Alderson, David L., Gerald G. Brown, and W. Matthew Carlyle. 2015. "Operational Models of Infrastructure Resilience.” Risk Analysis 35(4): 562-586.

Balasubramanian, R., and D. Agarwal. 2012. "Delphi Technique-A Review.” International Journal of Public Health Dentistry 3(2): 16-25.

Boring, R. L. 2007. "A Review of Expertise and Judgment Processes for Risk Estimation.” Proceedings of the European Safety and Reliability Conference (ESREL 2007), INL/CON-07-12774.

Cavalieri, F., P. Franchin, P. Gehl, and D. D’Ayala. 2017. "Bayesian Networks and Infrastructure Systems: Computational and Methodological Challenges.” Risk and Reliability Analysis: Theory and Applications. Edited by P. Gardoni. Springer International Publishing. https://doi.org/10.1007/978-3-319-52425-2_17

Christophersen, A., N. Delingne, A. Hanea, L. Chardot, N. Fournier, and W. Aspinall. 2018. "Bayesian Network Modeling and Expert Elicitation for Probabilistic Eruption Forecasting: Pilot Study for Whakaari/White Island, New Zealand." Frontiers in Earth Science 6(211): 1-23. https://doi.org/10.3389/feart.2018.00211

Dam, K. H., I. Nikolic, and Z. Lukszo. (Eds.). 2013. Agent-Based Modelling of SocioTechnical Systems. Netherlands: Springer. https://doi.org/10.1007/978-94-007-4933-7

Dam Safety Committee. 2010. "Reliability of Spillway Flow Control Systems." Dam Safety New South Wales. http://www.damsafety.nsw.gov.au/

DeNeale, S. T., G. B. Baecher, K. M. Stewart, E. D. Smith, and D. B. Watson. 2019. "Current State-Of-Practice in Dam Safety Risk Assessment." Oak Ridge National Laboratory. http://www.osti.gov/

Eisenberg, D., T. Seager, and D. L. Alderson. 2019. "Rethinking Resilience Analytics." Risk Analysis 39(9): 1870-1884. https://doi.org/10.1111/risa.13328

Hickey, A. M., and A. M. Davis. 2003. "Elicitation Technique Selection: How Do Experts Do It?” Journal of Lightwave Technology 169-178. https://doi.org/10.1109/ICRE.2003.1232748

Hossain, N. U. I., R. Jaradat, S. Hosseini, M. Marufuzzaman, and R. K. Buchanan. 2019a. "A Framework for Modeling and Assessing System Resilience Using a Bayesian Network: A Case Study of an Interdependent Electrical Infrastructure System." International Journal of Critical Infrastructure Protection 25: 62-83. https://doi.org/10.1016/j.ijcip.2019.02.002 
Hossain, N. U. I., F. Nur, S. Hosseini, R. Jaradat, M. Marufuzzaman, and S. M. Puryear. 2019b. "A Bayesian Network Based Approach for Modeling and Assessing Resilience: A Case Study of a Full Service Deep Water Port.” Reliability Engineering \& System Safety 189: 378-396. https://doi.org/10.1016/i.ress.2019.04.037

Jacob, C., D. Dubois, J. Cardoso, M. Ceberio, and V. Kreinovich. 2011. Estimating Probability of Failure of a Complex System Based on Partial Information about Subsystems and Components, with Potential Applications to Aircraft Maintenance. Technical Report UTEP-CS-11-23. https://scholarworks. utep.edu/cs techrep/615/

Koller, D., and N. Friedman. 2009. Probabilistic Graphical Models: Principles and Techniques. Massachusetts Institute of Technology: MIT Press.

Lewin, J., G. Ballard, and D. S. Bowles. 2003. Spillway Gate Reliability in The Context of Overall Dam Failure Risk. http://citeseerx.ist.psu.edu/viewdoc/summary?doi=10.1.1.65.8941

Mahmoodian, M., J. Phelan, and M. Shahparvari. 2017. "Reliability-Based Maintenance Management Methodology to Minimise Life Cycle Cost of Water Supply Networks." International Journal of Civil and Environmental Engineering 11(11): 11.

Marks, C., K. Smead, and J. Alt. 2013. Enhancing Subject Matter Expert Elicitation Techniques. TRAC-M-TR-13-048. Monterey, CA: TRADOC Analysis Center.

Miller, K. A., B. Collada, D. Tolliver, Z. Audi, A. Cohen, C. Michelson, and L. R. Newman. 2020. "Using the Modified Delphi Method to Develop a Tool to Assess Pediatric Residents Supervising on Inpatient Rounds." Academic Pediatrics 20(1): 89-96. https://doi.org/10.1016/i.acap.2019.07.012

NIAC (National Infrastructure Advisory Council). 2009. Critical Infrastructure Resilience Final Report and Recommendations. National Infrastructure Advisory Council. https://www.cisa.gov/sites/default/ files/publications/niac-critical-infrastructureresilience-final-report-09-08-09-508.pdf

Nunes, J., M. Barbosa, L. Silva, K. Gorgonio, H. Almeida, and A. Perkusich. 2018. "Issues in the Probability Elicitation Process of Expert-Based Bayesian Networks." Intech Open. https://dio.org/10.5772/intechopen.81602

Russell, S., and P. Norvig. 2010. Artificial Intelligence: A Modern Approach. 3rd ed. Upper Saddle River, NJ: Prentice Hall.

Salem, A. B., A. Muller, and P. Weber. 2006. "Dynamic Bayesian Networks in System Reliability Analysis." IFAC Proceedings Volumes 39(13): 444-449. https://doi.org/10.3182/20060829-4-CN-2909.00073

Scutari, M. 2019. "Bayesian Network Models for Incomplete and Dynamic Data." ArXiv:1906.06513 [Math, Stat]. http://arxiv.org/abs/1906.06513

Simon, C., P. Weber, and E. Levrat. 2007. "Bayesian Networks and Evidence Theory to Model Complex Systems Reliability.” Journal of Computers 2(1): 33-43. https://doi.org/10.4304/jcp.2.1.33-43 
Teter, M. 2014. Applying Subject Matter Expert (SME) Elicitation Techniques to TRAC Studies. TRAC-M-TR-14-036. Monterey, CA: TRADOC Analysis Center.

Thomas, J. E., D. A. Eisenberg, T. P. Seager, and E. Fisher. 2019. “A Resilience Engineering Approach to Integrating Human and Socio-Technical System Capacities and Processes for National Infrastructure Resilience." Journal of Homeland Security and Emergency Management 16(2). https://doi.org/10.1515/ihsem-2017-0019

Tien, I., and A. Der Kiureghian. 2016. "Algorithms for Bayesian Network Modeling and Reliability Assessment of Infrastructure Systems.” Reliability Engineering \& System Safety 156: 134-147. https://doi.org/10.1016/j.ress.2016.07.022

USACE (US Army Corps of Engineers). 2019. US Army Corps of Engineers Policy for Operational Condition Assessments for USACE Assets. USACE EC 11-2-218. Washington, DC: USACE.

USACE. (n.d.). Introduction to Risk Assessment. Washington, DC: USACE.

Uusitalo, L. 2007. "Advantages and Challenges of Bayesian Networks in Environmental Modeling." Ecological Modeling 203: 312-318. https://doi:10.1016/j.ecolmodel.2006.11.033

Vugrin, E. D., D. E. Warren, and M. A. Ehlen. 2011. "A Resilience Assessment Framework for Infrastructure and Economic Systems: Quantitative and Qualitative Resilience Analysis of Petrochemical Supply Chains to a Hurricane. Process Safety Progress 30(3): 280-290. https://doi.org/10.1002/prs.10437

Wilson, A. G., and K. M. Fronczyk. 2016. "Bayesian Reliability: Combining Information.” Quality Engineering 29(1). https://doi.org/10.1080/08982112.2016.1211889

Yontay, P. 2016. A Bayesian Network Approach to Early Reliability Assessment of Complex Systems. PhD dissertation. Arizona State University. 


\section{Appendix: Jennings Randolph Lake OCAs}

Table 2. Count of unique OCAs associated with each system for Jennings Randolph Lake. The count represents the sum of the OCAs present in the data set across all components associated with the system.

\begin{tabular}{|c|c|}
\hline & Jennings Randolph Lake \\
\hline Bridges & 18 \\
\hline Buildings & 81 \\
\hline Dam Sections & 6 \\
\hline Dike Sections & 5 \\
\hline Discharge Works & 27 \\
\hline Electrical Power Systems & 105 \\
\hline Hydraulic Power Systems & 13 \\
\hline Intake Works & 15 \\
\hline Miscellaneous Site Features & 16 \\
\hline Miscellaneous Use Service Cranes and Hoists & 115 \\
\hline Monitoring Systems & 7 \\
\hline Project Lighting & 47 \\
\hline Project Safety & 1 \\
\hline Project Utilities & 21 \\
\hline Real Estate & 6 \\
\hline Spillway Gates & 120 \\
\hline Water Quality Gates and Valves & 29 \\
\hline
\end{tabular}




\title{
Acronyms and Abbreviations
}

\author{
CWMS Corps Water Management System \\ ERDC US Army Engineer Research and Development \\ FEM Facilities and Equipment Maintenance \\ FRM Flood Risk Management \\ IWR from Institute for Water Resources \\ OCA Operational Condition Assessments \\ PoF probability of failure \\ SME $\quad$ subject matter expert \\ STS socio-technical systems \\ USACE US Army Corps of Engineers
}










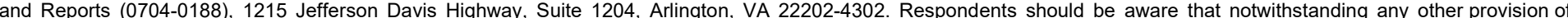
law, no person shall be subject to any penalty for failing to comply with a collection of information if it does not display a currently valid OMB control number. PLEASE DO NOT RETURN YOUR FORM TO THE ABOVE ADDRESS.

\begin{tabular}{l|l|l}
$\begin{array}{l}\text { 1. REPORT DATE } \\
\text { March } 2021\end{array}$ & $\begin{array}{l}\text { 2. REPORT TYPE } \\
\text { Final Report }\end{array}$ & 3. DATES COVERED (From - To)
\end{tabular}

\section{TITLE AND SUBTITLE}

Final Report

\section{Risk-Based Prioritization of Operational Condition Assessments: Stakeholder Analysis and}

Literature Review

5a. CONTRACT NUMBER

5b. GRANT NUMBER

5c. PROGRAM ELEMENT NUMBER

\section{AUTHOR(S)}

Jonathan K. Alt, Willie H. Brown, George E. Gallarno, and John P. Richards 5d. PROJECT NUMBER

5e. TASK NUMBER

5f. WORK UNIT NUMBER

8. PERFORMING ORGANIZATION REPORT NUMBER

ERDC/ITL SR-21-2

10. SPONSOR/MONITOR'S ACRONYM(S) NavSys

11. SPONSOR/MONITOR'S REPORT NUMBER(S)

Vicksburg, MS 39180-6199

\section{DISTRIBUTION/AVAILABILITY STATEMENT}

Approved for public release; distribution is unlimited.

\section{SUPPLEMENTARY NOTES}

Funding Account Code U4375151; AMSCO Code 031391

\section{ABSTRACT}

The US Army Corps of Engineers (USACE) operates, maintains, and manages more than \$232 billion worth of the Nation's water resource infrastructure. Using the Operational Condition Assessment (OCA) system, the USACE allocates limited resources to assess conditions and maintain assets in efforts to minimize risks associated with asset performance degradation. Currently, OCAs are conducted on each component within a facility every 5 years, regardless of the component's risk contribution. The analysis of risks associated with Flood Risk Management (FRM) facilities, such as dams, includes considering how the facility contributes to its associated FRM watershed system, understanding the consequences of degradation in the facility's performance, and calculating the likelihood that the facility will perform as expected given the current OCA condition ratings of critical components. This research will develop a scalable methodology to model the probability of failure of components and systems that contribute to the performance of facilities in their respective FRM systems combined with consequences derived from hydrological models of the watershed to develop facility risk scores. This interim report documents the results of the first phase of this effort, stakeholder analysis and literature review, to identify candidate approaches to determine the probability of failure of a facility.

\section{SUBJECT TERMS}

Civil engineering-Management, Flood damage prevention, Hydrological models, Risk assessment, Risk management

\section{SECURITY CLASSIFICATION OF:}

\begin{tabular}{|l|c|l|}
\hline a. REPORT & b. ABSTRACT & c. THIS PAGE \\
Unclassified & Unclassified & Unclassified \\
\hline
\end{tabular}

17. LIMITATION OF ABSTRACT

SAR
18. NUMBER

OF PAGES

40 19a. NAME OF RESPONSIBLE PERSON Willie H. Brown

19b. TELEPHONE NUMBER (Include area code) 610-634-4199 